\title{
Combination of low-pressure UF membranes with conventional water treatment systems
}

\author{
Karali I. ${ }^{1,}{ }^{*}$, Çakmakci M. ${ }^{2}$, Koyuncu I. ${ }^{3}$, Demir A. ${ }^{2}$ and Karadag D. ${ }^{2}$ \\ ${ }^{1}$ Istanbul Water and Sewerage Administration (ISKI), Kağithane, Istanbul, Turkey \\ ${ }^{2}$ Yildiz Technical University, Department of Environmental Engineering, Esenler, Istanbul, Turkey \\ ${ }^{3}$ Istanbul Technical University, Department of Environmental Engineering, Sariyer, Istanbul, Turkey \\ Received: 09/08/2017, Accepted: 28/08/2017, Available online: 09/11/2017 \\ *to whom all correspondence should be addressed: e-mail: ibrahimkarali@hotmail.com
}

\begin{abstract}
The purpose of the study was to improve drinking water quality of conventional treatment processes by combining with UF-membrane systems. Performances of two membrane systems were evaluated in two different fullscale conventional water treatment plants in Istanbul. Lowpressure UF membranes were combined after settling and filtration units of Büyükçekmece and Emirli water treatment plants. Low-pressure UF systems were operated under vacuum and pressure conditions. The experimental results indicated that combining UF systems enhanced drinking water quality with respect to turbidity, TOC and $\mathrm{UV}_{254}$ removal. In all cases, vacuum-driven UF membranes provided higher treatment performance and low energy consumption comparing to pressure-driven system. Combination with UF membranes also reduced disinfection by-products.
\end{abstract}

Keywords: drinking water; low-pressure UF; conventional treatment; turbidity; TOC

\section{Introduction}

In most parts of the world, conventional treatment technologies are widely employed for the production of drinking water from surface water. Water production by conventional treatment is accomplished through separation of contaminants and microorganisms by physical and chemical methods, and disinfection. A conventional water treatment plant consists of basic units of aeration, coagulation, flocculation, sedimentation, filtration and disinfection (Shao et al., 2015). In addition to those, one or more units of activated carbon filtration, ozone oxidation, ion exchange etc can be included based on the feed water characteristics and required effluent quality (Papageorgiou et al., 2016; Stoquart et al., 2012). Excessive mechanical equipment and use of chemicals increase the capital and operational costs of conventional treatment plants. In addition to having difficulty to remove micro pollutants, high requirement of qualified technical personnel and additional treatment for chemical waste stream are other shortcomings of conventional systems (Plakas and Karabelas, 2012). In conventional treatment plants, application of chlorination to remove bacteria and viruses causes the formation of disinfection by-products which have adverse effect on human health (Ang et al., 2015).

Membrane filtration systems are superior over conventional technologies with the advantages of simplicity, removal of nano-scale contaminants and viruses, and production of high quality drinking water (Bogati et al., 2015). With the use of membrane systems, all soluble, colloidal and macro pollutants can be physically separated from water. Membrane plants with automatic control systems also declines personnel requirement. In recent few decades, membrane technologies have been extensively used for drinking water production separately or combination with conventional treatment plants (Cakmakci et al., 2009; Metsämuuronen et al., 2014; Mehwish et al., 2014). On the other hand, rapid improvements in membrane production technology, decrease is cost, less ground requirement with compact systems, absence of chemical use and stringent drinking water regulations have favoured the installation of membrane plants around the world. Membrane systems are also able to eliminate hazardous by-products and constantly produce high quality water regardless with the changes in the surface water quality (Qin, et al., 2012; Uyak et al., 2008). The main bottleneck of membrane technologies is the high energy consumption which increases proportionally with the pressure applied. However, this costly drawback can be overcome by using low-pressure membrane systems. Nowadays, scientific researches have been mostly focused on low-pressure UF membrane systems for drinking water production (Yamamura et al., 2015). Low-pressure UF systems have been enumerated as a very promising process for drinking water production with respect to its compactness, easy automation, relatively low cost, and excellent rejection performance of turbidity, organic matters and microorganism (Gao et al., 2011; Bai et al., 2015). However, pre-treatment could increase treatment efficiency and service life of UF membrane along with the reduction in energy consumption (Rojas-Serranoa et al., 2015; Huang et al., 2009). For instance, Study of 
Choksuchart et al., (2002) indicated that coagulation is a necessary pre-treatment step before drinking water production by UF membranes. Without pre-treatment rapid deposit of suspended clay particles clog membrane pores and declines membrane flux. Similarly, Chen and Deng (2004) found that pre-treatment by electrocoagulation can increase humic acids rejection by UF membrane and reduce membrane fouling and transmembrane pressure.

For drinking water production, low-pressure UF membranes can be operated after a pre-treatment of feed water. On the other hand, it can be combined with different stage of the conventional plant and existing prior units operates as pre-treatment units. In this work, pilotsale UF membranes were installed after settling and filtration units of conventional water treatment plants. All treatment plants in Istanbul have conventional technologies and there is no membrane plant for water purification. Studies were performed in Büyükçekmece and Emirli water treatment plants in Istanbul. Vacuum-driven and pressure driven low-pressure UF systems were evaluated based on the improvements in turbidity and TOC removal and energy consumption. To our knowledge, there is no detailed study on combination of low-pressure UF membrane systems with the existing conventional water treatment plants in Istanbul.

\section{Materials and Methods}

\subsection{Conventional water treatment plants}

Büyükçekmece water treatment plant (BWTP) is located in the European side of Istanbul and its water production capacity is $400,000 \mathrm{~m}^{3}$ per day. Feed water is received from Lake Büyükçekmece by pipeline and it is coagulated using $\mathrm{Al}_{2}\left(\mathrm{SO}_{4}\right)_{3}$ and separated in up-flow sedimentation tank. Emirli water treatment plant (EWTP) is in the Asian side of the city and its water production capacity is $500,000 \mathrm{~m}^{3}$ per day. EWTP receives feed water from four surface reservoirs; thus it has high seasonal variation in water characteristics. Different from BWTP, $\mathrm{FeCl}_{3}$ is used as coagulant and EWTP has Pulsator Clarifier sedimentation tank. Both plants have pre-chlorination units and purified water is disinfected by chlorine at the final stage before serving to the distribution line.

The characteristics of feed were as shown in Table 1. As evident from the table, both feed water had different water characteristics. Except colour, feed water of BWTP was generally had higher contaminant concentrations than EWTP. Since feed the water was obtained from reservoirs, turbidity values were mostly in low concentration whereas slight increase was observed during rainy days.

Table 1. Water characteristics of feed water

\begin{tabular}{lccc}
\hline Parameter & Unit & Büyükçekmece & Emirli \\
\hline Turbidity & $\mathrm{NTU}$ & $1.74-55.2$ & $0.98-33.2$ \\
\hline TOC & $\mathrm{mg} \mathrm{L}^{-1}$ & $4.99-6.09$ & $2.84-4.85$ \\
\hline Conductivity & $\mu \mathrm{cm}^{-1}$ & $517-613$ & $232-426$ \\
\hline Colour & $\mathrm{Pt-Co}$ & $5-40$ & $7.5-70$ \\
\hline $\mathrm{pH}$ & & $7.79-8.47$ & $7.25-8.12$ \\
\hline Total hardness & $\mathrm{mg} \mathrm{L}^{-1} \mathrm{CaCO}_{3}$ & $182-224$ & $82-240$ \\
\hline Total alkalinity & $\mathrm{mg} \mathrm{L}^{-1} \mathrm{CaCO}_{3}$ & $122-170$ & $74.2-233$ \\
\hline $\mathrm{Cl}$ & $\mathrm{mg} \mathrm{L}^{-1}$ & $38.6-58$ & $7.1-19$ \\
\hline $\mathrm{NH}_{3}$ & $\mathrm{mg} \mathrm{L}^{-1}$ & $0.03-0.82$ & $0-0.03$ \\
\hline $\mathrm{Fe}^{+3}$ & $\mathrm{mg} \mathrm{L}^{-1}$ & $0.06-0.81$ & $0.03-0.19$ \\
\hline $\mathrm{Mn}^{+2}$ & $\mathrm{mg} \mathrm{L}^{-1}$ & 0.0 & $0.0-0.02$ \\
\hline
\end{tabular}

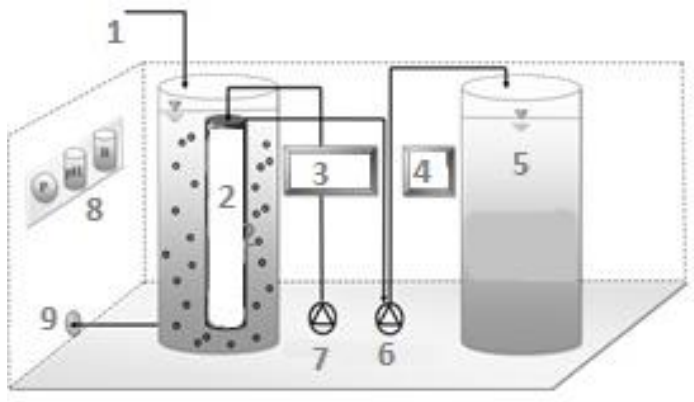

Figure 1. Schematic diagram of membrane systems: 1) Raw water, 2) Membrane module, 3) Data logger,4)PLC, 5)Clean water tank, 6) Vacuum and recycling pump, 7) Air pump, 8) Pressure, $\mathrm{pH}$ and turbidity meters, 9) Discharge

\subsection{Pilot-scale UF membranes}

Pilot-scale UF systems were operated parallel with conventional treatment processes. In both conventional treatment plants, pilot-scale UF systems were fed by the effluents from sedimentation and filtration units.

Schematic diagrams of pilot-scale UF systems are given in Figure 1 and technical features of membranes are in Table 2. Low-pressure pilot-scale UF systems were operated 
under vacuum and pressure conditions. Vacuum-driven pilot-scale UF system was designated as V-PSUF and pressure-driven was designated as P-PSUF. Both systems were equipped with online measurement probes for the determination of $\mathrm{pH}$, turbidity, flow rate and TMP. V-PSUF was configured with a membrane module of hydrophilic ZW10 from Zenon Environmental Inc. (Canada). Membrane module has surface area of $0.93 \mathrm{~m}^{2}$ surface area and it was backwashed for 30 seconds using clean water after sixminute operation. V-PSUF operation was performed at fixed flow rate of $40 \mathrm{Lh}^{-1}$. Since the membrane module is susceptible to the changes in $\mathrm{pH}$, feed water $\mathrm{pH}$ was

Table 2. Technical characteristics of membranes maintained at $7.5 \pm 0.3$ through $\mathrm{HCl}$ or $\mathrm{NaOH}$ adding by automatic $\mathrm{pH}$ control unit. P-PSUF had similar configurations except with the membrane modules. PPSUF was equipped with 4100 UF/MB membranes from IMT Membranes B.V (Holland) having $5.8 \mathrm{~m}^{2}$ surface area. Membranes were operated as dead-end mode and regularly backwashed once after one-hour operation or when TMP was at maximum pressure. Backwash was conducted at 4 bar by sequence of acid washing $(4 \mathrm{~g} \mathrm{HCl} / \mathrm{L})$ for 60 seconds, alkaline washing $\left(20 \mathrm{~g} \mathrm{NaOH} \mathrm{L}^{-1}\right)$ for 120 seconds and $28 \mathrm{ppm} \mathrm{NaOCl}$ for 40 seconds.

\begin{tabular}{c|cc}
\hline & ZW10 & 4100 UF/MB \\
\hline Membrane material & PVDF & 0.01 \\
\hline Pore size $(\mu \mathrm{m})$ & 0.04 & 10 \\
\hline Maximum pressure $(\mathrm{bar})$ & 0.6 & $<1$ \\
\hline Operational TMP $(\mathrm{bar})$ & $0.07-0.5$ & 2.5 \\
\hline Maximum TMP $(\mathrm{bar})$ & -1 & $100-350$ \\
\hline Filtrate flow rate $\left(\mathrm{L} \mathrm{m}^{-2} \cdot \mathrm{h}^{-1}\right)$ & $60-130$ & $3-10$ \\
\hline $\mathrm{pH}$ & $5-9$ &
\end{tabular}

\subsection{Analysis}

$\mathrm{pH}$ measurements were performed by a Endress+Hauser $\mathrm{pH}$ meter in V-PSUF and a Hach-Lange $\mathrm{pH}$ meter in P-PSUF. Turbidity measurements were conducted by by Endress+Hauser turbidity meter in PSUF1 and Hach-Lange turbidity meter in P-PSUF. Concentration of total organic carbon (TOC) was determined by Shimadzu TOC analyzer ( $\mathrm{V}_{\mathrm{CPH}}$ Model). UV absorbance at $254 \mathrm{~nm}$ was used as an index of the natural organic matter and it was measured by a UV spectrophotometer (Shimadzu-UV-1800 Model). Feed water samples were initially filtered initially filtered through a $0.45-\mu \mathrm{m}$ membrane before analysis while water samples of membrane effluents were directly analysed. Trihalomethane formation potential (THMFP) tests were performed by purge-trap method based on Standard Methods.

\section{Results and Discussion}

3.1 Molecular weight distribution of organics in conventional treatment plants

Table 3. Changes in molecular weight of organic matters in conventional water treatment plants

\begin{tabular}{ccccccc}
\hline & \multicolumn{2}{c}{ Büyükçekmece Water Treatment Plant (\%) } & \multicolumn{3}{c}{ Emirli Water Treatment Plant (\%) } \\
\hline MW (Da) & Feed water & Sedimentation & Filtration & Feed water & Sedimentation & Filtration \\
\hline$>3000$ & 19 & 18.6 & 10.9 & 21.7 & 15.8 & 16.6 \\
\hline $3000-1000$ & 8.6 & 7.5 & 12.2 & 7.5 & 12.3 & 9 \\
\hline$<1000$ & 72.4 & 73.9 & 76.9 & 70.8 & 71.9 & 74.4 \\
\hline
\end{tabular}

\subsection{Turbidity removal}

Variations in turbidity values of effluents from pilot-scale UF membranes were as shown in Figures 2 and 3. In addition, turbidity ranges in feed water, effluents from conventional and UF systems along with other contaminants and operational conditions were
The changes in the molecular weight (MW) of organics in feed water and after sedimentation and filtration units were as given in Table 3. Feed water of two plants had similar molecular organics with slightly different percentages. In both feed water, organics were mainly composed of smaller molecules with MW of less than 1000 Da while the least ratios were distributed in the 1000-3000 Da. MW distribution of organics slightly altered following the conventional treatment processes in both plants with the transformation of higher molecules into smaller size. Ratios of organics with higher than 3000 Da gradually declined along treatment units due to the retention in sedimentation and filtration units. On the other hand, ratios of organics less than 1000 Da slightly increased after each treatment unit. However, distribution of organics between 1000 and 3000 Da fluctuated after sedimentation and filtration processes and increased in the effluents of plants. Consequently, it can be concluded that conventional treatment processes had little effect on the distribution of organic molecules. 
filtration units had less than 0.5 NTU. In most operational time of both UF systems in BWTP, turbidity was less than 0.05 NTU while P-PSUF effluent after filtration was less than 0.03 NTU. The sharp increases in turbidity values in the figures were probably resulted with the entrance of air bubbles into turbidity meter. V-PSUF in EWTP exhibited stabile turbidity between 0.01-0.03 NTU whereas effluents from P-PSUF after both sedimentation and filtration units were fluctuated with less than 0.05 NTU.

In the case of BWTP, turbidity was in the range of 0.23 to 0.96 NTU in sedimentation effluent and 0.12 to 0.41 NTU in filtration effluent. According to these values, sedimentation provided $99.1 \%-99.5 \%$ turbidity removal and half of the remaining turbidity was removed by subsequent filtration unit. After conventional sedimentation and filtration units, turbidity was 0.01-0.03 NTU in V-PSUF effluent and 0.01-0.10 NTU while in P-PSUF effluent was. In all cases, combination with pilot-scale plants exhibited turbidity removal efficiencies between 99.0 and $99.9 \%$ while vacuum-driven UF was superior on pressure-driven system. Additionally, figures indicate that combination with low-pressure UF systems provided excellent water quality with less than 0.1 NTU regardless with the influent turbidity.
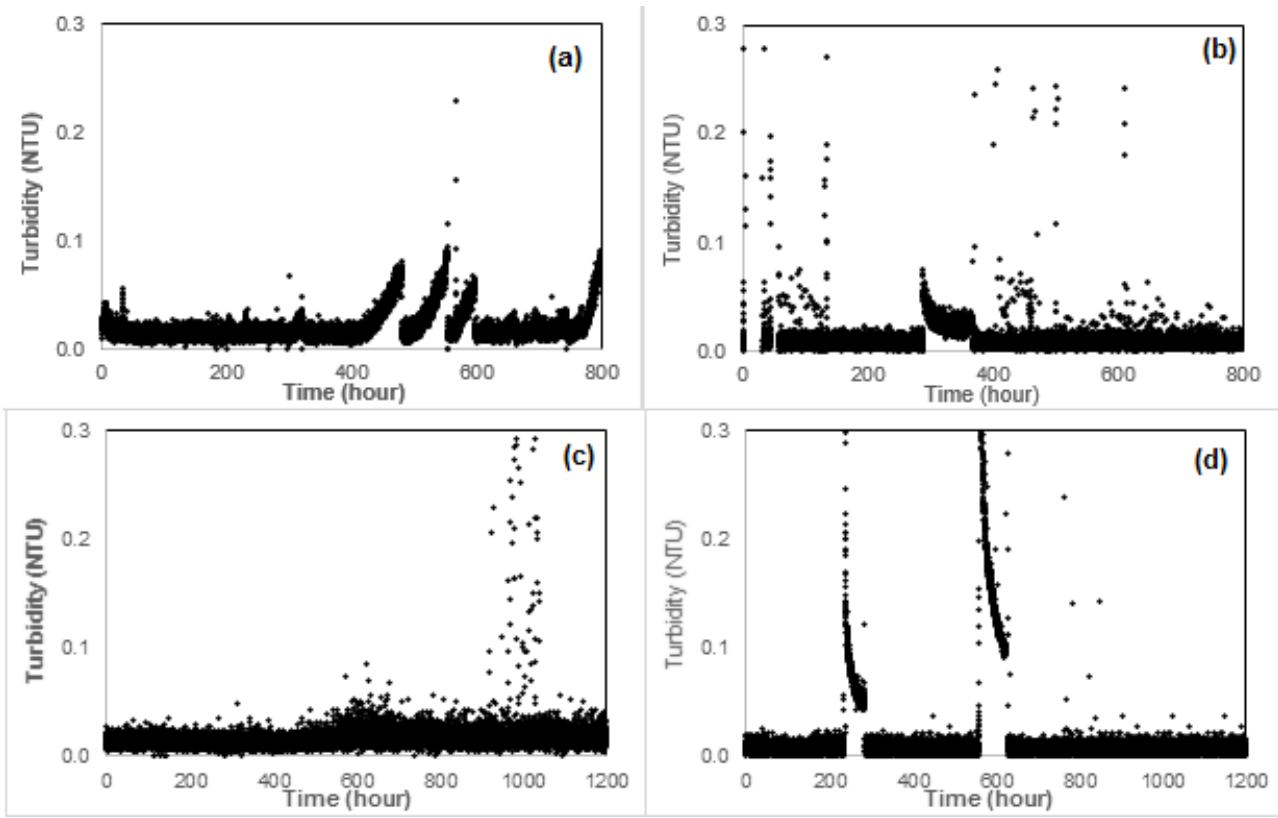

Figure 2. Effluent turbidity values of (a) V-PSUF and (b) P-PSUF combination with sedimentation and (c) V-PSUF, (d) PPSUF combination with filtration in Büyükçekmece treatment plant
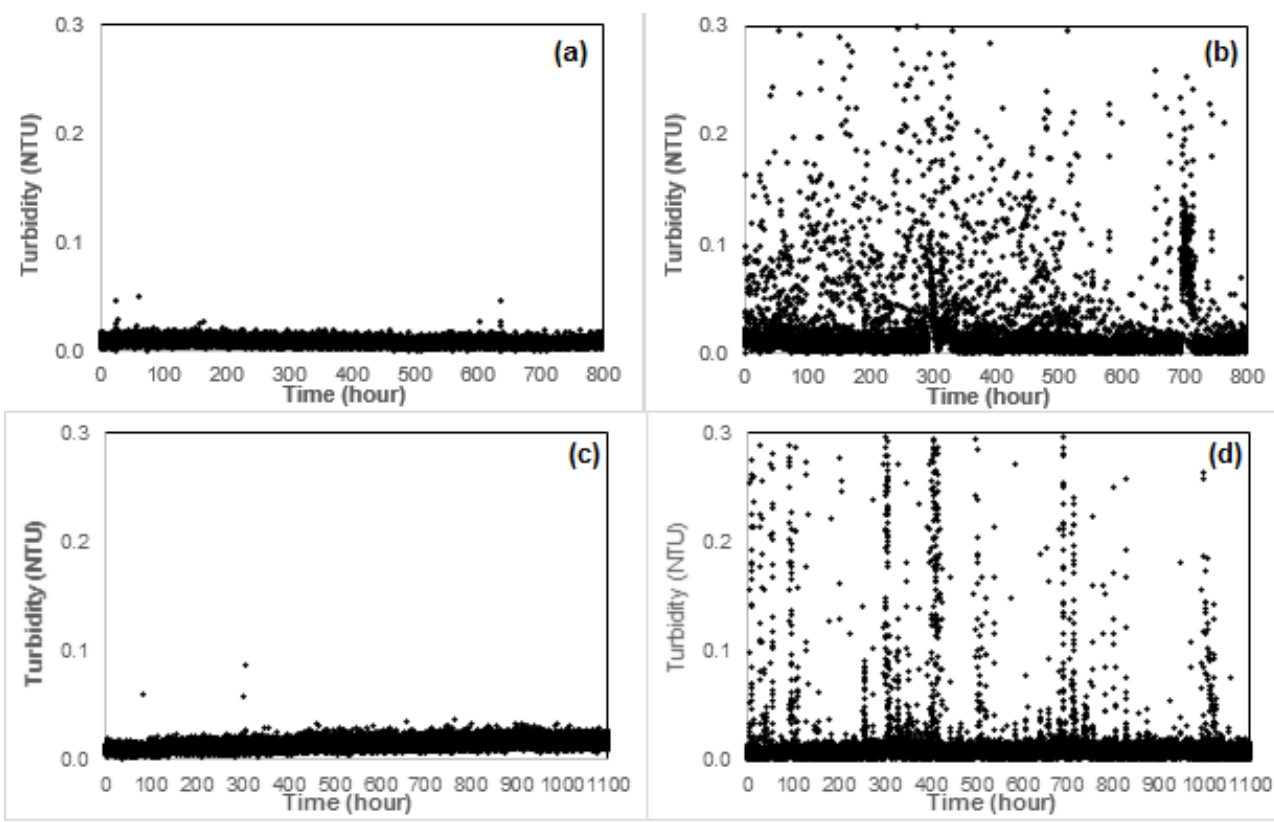

Figure 3. Effluent turbidity values of (a) V-PSUF and (b) P-PSUF combination with sedimentation and (c) V-PSUF, (d) PPSUF combination with filtration in Emirli treatment plant 


\subsection{Organic matter removal}

TOC values in the feed water of BWTP were 4.65 to $5.93 \mathrm{mg}$ $\mathrm{L}^{-1}$ and 3.43-5.80 in EWTR, respectively. TOC reduced to 3.26-4.48 $\mathrm{mg} \mathrm{L}^{-1}$ after sedimentation and 2.82-4.53 $\mathrm{mg} \mathrm{L}^{-1}$ after filtration. These values indicates that sedimentation process had higher TOC removal efficiency comparing filtration unit. Effluent TOC values in V-PSUF combination with sedimentation was 3.42-3.95 $\mathrm{mg} \mathrm{L}^{-1}$ whereas effluent of with P-PSUF was 3.73-4.40 $\mathrm{mg} \mathrm{L}^{-1}$ (Figure 4). In respect to combination with filtration, TOC values were 2.67-4.38 $\mathrm{mg} \mathrm{L}^{-1}$ in V-PSUF and 3.12-4.46 in P-PSUF. Comparison of influent and effluent TOC values in both combined systems revealed that TOC removal efficiencies of combined V-PSUF and P-PSUF were between 10 and 20\%, 0 and 5\%, respectively. These values indicates that both combined UF systems provided slight TOC elimination while vacuumdriven system was better than pressure-driven UF. In EWTP, feed water had $3.43-5.80 \mathrm{mg} / \mathrm{L}$ TOC values and it decreased to $1.88-3.55 \mathrm{mg} \mathrm{L}^{-1}$ after sedimentation and 1.00 to $2.41 \mathrm{mg} \mathrm{L}^{-1}$ after filtration. In combination with sedimentation, V-PSUF provided about $20 \%$ TOC removal and P-PSUF had 5-10\% treatment efficiencies with effluent TOC value of 1.67-2.93 $\mathrm{mg} \mathrm{L}^{-1}$ and 1.91-3.09 $\mathrm{mg} \mathrm{L}^{-1}$. On the other hand, V-PSUF had $10-20 \%$ removal efficiency after filtration while P-PSUF had no treatment efficiency. Application of low-pressure UF combination with filtration provided 0.81-2.20 TOC $\mathrm{mg} \mathrm{L}^{-1}$ with V-PSUF and 0.89-2.32 TOC mg L $\mathrm{L}^{-1}$ P-PSUF. Less TOC removal efficiencies by pilot systems on the effluents of sedimentation and filtration processes was associated with the presence of low organic matters in the effluent. Membranes with the pore sizes of $0.04 \mu \mathrm{m}$ and $150 \mathrm{Da} \mathrm{MW}$ had low rejection efficiencies with smaller size molecules. Total evaluation indicated that combined effect of coagulation, sedimentation and filtration with UF membrane provided better water quality with respect to organic removal. On the other hand, vacuum-driven UF had better performance on TOC elimination than pressure-driven system.

$U_{254}$ was between 0.05 and $0.07 \mathrm{~cm}^{-1}$ in the feed water of BQTP and it decreased to 0.04-0.06 after sedimentation and 0.04-0.05 after filtration. Combination with V-PSUF provided $40-50 \%$ removing efficiency while P-PSUF had $10-$ $30 \%$ after sedimentation while both UF systems had no removing of $U V_{254}$ after filtration unit. $U_{254}$ was in the range of 0.06 to $0.11 \mathrm{~cm}^{-1}$ in the feed water of EWTP while it reduced to $0.04-0.07$ and $0.02-0.03 \mathrm{~cm}^{-1}$ in the effluents of sedimentation and filtration processes. V-PSUF had $25 \%$ and $30-50 \%$ removal efficiencies after sedimentation and filtration whereas combination with P-PSUF provided $25 \%$ and $0 \%$. These values indicated that vacuum driven UF system was more efficient on the removal of natural organic matters.
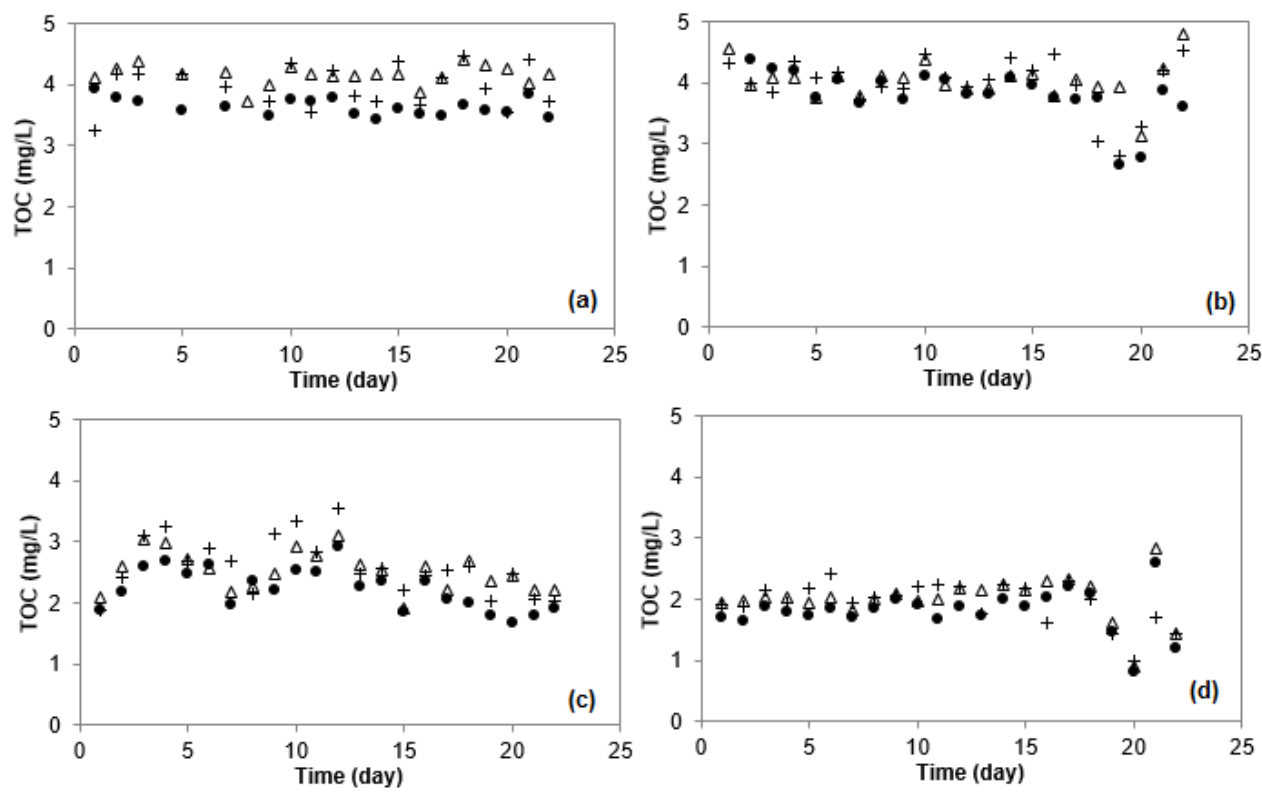

Figure 4. Changes in TOC of feed water $\left({ }^{+}\right), \operatorname{V-PSUF}(\bullet)$ and P-PSUF $\left(\Delta^{l}\right)$ in BWTP (a) and (b), in EWTP (c) and (d)

\subsection{Evaluation of total coliform removal and Trihalomethane formation potential}

There was 4-370 MPN/100 ml total coliform in the feed of EWTP and 4-60 MPN per $100 \mathrm{ml}$ in the feed water of BWTP. Pre-chlorination in conventional treatment processes eliminated all coliforms and influents of UF membranes were absent of microorganisms. Therefore, conventional treatment processes are efficient to remove all total coliforms and membrane systems had no effect on microorganism removal.
In water treatment plants, disinfection is applied to remove possible microorganism in the effluent and to prevent infection in downstream distribution lines. However, disinfectants can react with dissolved organic matters and form disinfection by-products. Trihalomethanes (THMs) are formed when chlorine is used as disinfectant and presence of THMs is a major challenge in the effluent of drinking water treatment plants due to the its potential carcinogenic effect on human health (Yang et al., 2015). Trihalomethane formation potential (THMFP) tests were performed only in Emirli water treatment plant. In 
conventional process effluents, THMFP values after filtration were lower than $100 \mu \mathrm{g} \mathrm{L}^{-1}$. Combination of pilot systems after sedimentation tank reduced THMFP about $13 \%$ by V-PSUF and $45 \%$ by P-PSUF. At the same time, THMFP after filtration was decreased about $1 \%$ by U-PSUF and $46 \%$ by P-PSUF. Comparing to conventional treatment process alone, combining with low-pressure UF membranes were more effective to eliminate THMFP. This was related with the higher organic matter removal with the combination of conventional processes and membrane systems.

\subsection{Changes in TMP}

During the operation of V-PSUF combination with sedimentation in Büyükçekmece water treatment plant, TMP increased up to 150 mbar after filtration time of 700 hours (Figure 5a). After filtration time of $400 \mathrm{~h}$, lowpressure UF membrane was backwashed by using chemicals and filtration was continued by using a spare membrane. The sharp change in TMP was due to effect of new membrane use. On the other hand, TMP values were relatively low and filtration time was considerably longer in the V-PSUF operation at filtration unit. Maximum TMP was $40 \mathrm{mbar}$ and filtration was performed up to $1250 \mathrm{~h}$. Low level TMP and longer filtration time was probably resulted from higher water quality after filtration compared to sedimentation in conventional treatment plant.
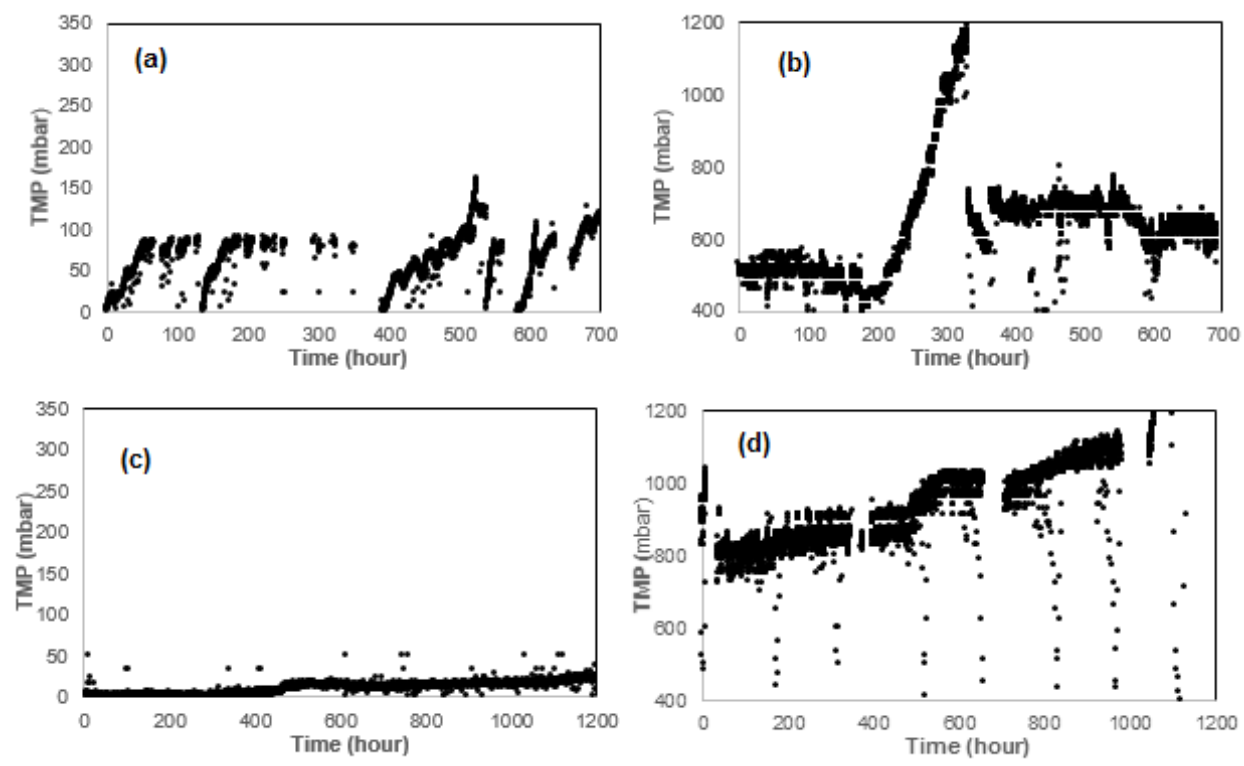

Figure 5. TMP of (a) V-PSUF and (b) P-PSUF combination with sedimentation, and (c) V-PSUF and (d) P-PSUF combination with filtration in Büyükçekmece treatment plant

In the case of P-PSUF operation combined with filtration unit, TMP varied between 400-750 mbar (Figure 6b). Under similar operational conditions with V-PSUF, sharp increase in TMP of P-PSUF was possibly because of the difference in operational mode. Dead-end filtration of pressure-driven membrane experienced sharp increase in TMP in relatively short filtration time and membrane were frequently backwashed using chemicals. TMP was reached up to 1200 mbar between filtration times of 200 and $330 \mathrm{~h}$ and it suddenly declined to 700 mbar after chemical backwashing. The changes in TMP of P-PSUF had strong negative influences on flow rate, whereas V-PSUF was operated at constant flow rate of $40 \mathrm{~L} \mathrm{~h}^{-1}$. Flow rate of $\mathrm{P}$ PSUF decreased up to $100 \mathrm{~L} \mathrm{~h}^{-1}$ at elevated TMP values while it increased up to $270 \mathrm{~L} \mathrm{~h}^{-1}$ after backwashing. On the other hand, flow rate remained 200-300 $\mathrm{L} \mathrm{h}^{-1}$ during the operation after conventional filtration unit which was strongly related with the cleaner effluent.

In the operation of UF systems in Emirli water treatment plant, maximum TMP was 45 mbar in V-PSUF after $800 \mathrm{~h}$ filtration time, whereas it varied between 600 to 1800 mbar in P-PSUF. Low TMP values in V-PSUF was directly proportional with the higher water quality after conventional sedimentation unit. Similar to Büyükçekmece plant, flow rate of P-SUF in EWTP was fluctuated with the variations with pressure. Flow rate of P-PSUF decreased to $60 \mathrm{l} / \mathrm{h}$ at maximum TMP while it increased up to $200 \mathrm{~L} \mathrm{~h}^{-1}$ after chemical backwashing. Operation of P-PSUF on the effluent of conventional filtration unit resulted longer service time and lower TMP. During the all experimental studies, the lowest TMP values were obtained by V-PSUF and TMP remained between 0-30 mbar. Under the same filtration duration of $1100 \mathrm{~h}$, TMP of P-PSUF varied between 600-2000 mbar. Frequent chemical backwashing was applied on P-PSUF due to fouling and TMP decreased around 700 mbar after each backwashing. In comparison to Büyükçekmece, the lowest flow rate during the operation of P-SUF at maximum TMP in EWTP was higher. Flow rate declined to $150 \mathrm{~L} \mathrm{~h}^{-1}$ at elevated TMP and it increased over $200 \mathrm{~L} \mathrm{~h}^{-1}$ after chemical washing. This difference was associated with the low contaminants level in feed water of EWTP.

General evaluation of experimental studies reveal that TMP values decreases with the combination of UF 
membrane more conventional treatment units. Moreover, Emirli plant had lower TMP values than Büyükçekmece.
TMP values gradually increased and flow rate decreased in P-PSUF since it was operated as dead-end mode.
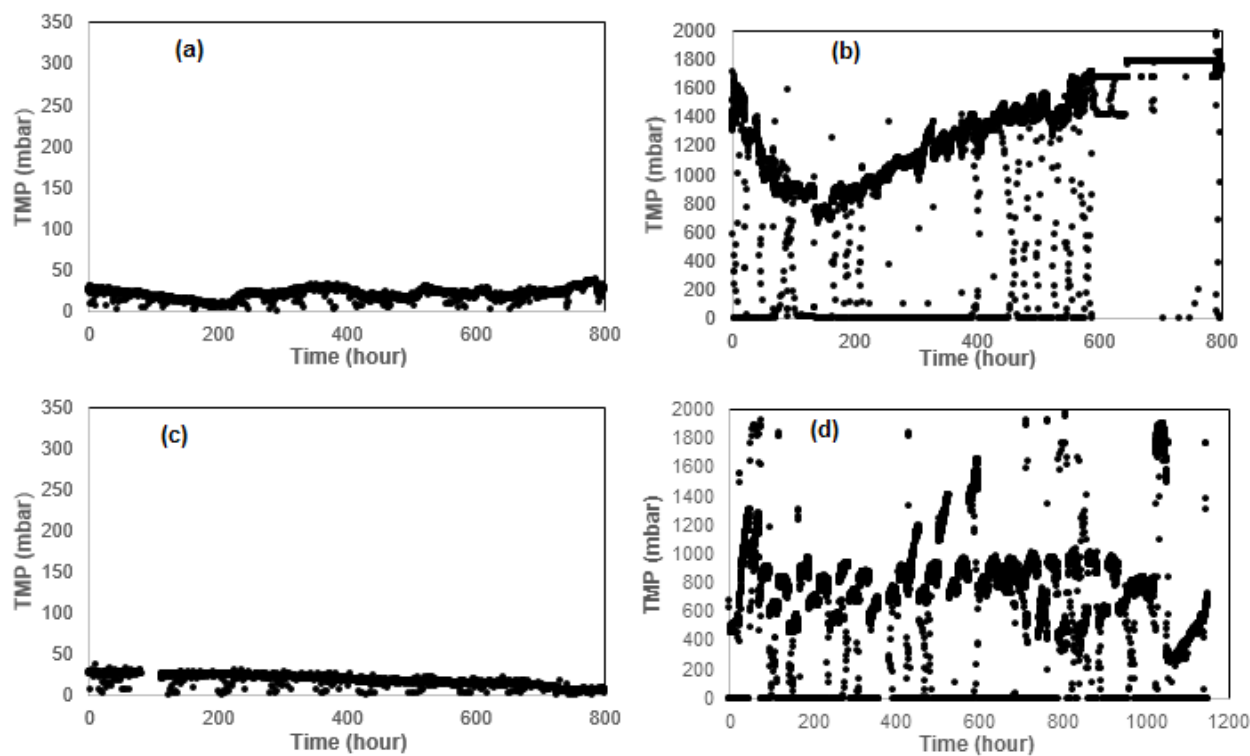

Figure 6. TMP of (a) V-PSUF and (b) P-PSUF combination with sedimentation, and (c) V-PSUF and (d) P-PSUF combination with filtration of Emirli treatment plant

Comparing two systems indicated that vacuum-driven system had lower TMP values than pressure-driven. Reduction in TMP caused by fouling requested frequent backwashing in pilot plants. In membrane operation, fouling plays a major role in membrane operation and it is caused by the accumulation of colloidal matters, organic and inorganic compounds and microorganism on the membrane surface and within membrane pores. Moreover, fouling results reduction in membrane production capacity, increase in pressure required, energy consumption and operational cost while membrane service life reduces with the deterioration of membrane materials (Shamsuddin et al., 2015; Xu et al., 2014). In our studies, there was no microorganism in the effluent of conventional sedimentation and filtration units. On the other hand, organic matter retention by both pilot-scale UF membranes remained very low. Therefore, it can be concluded that increase in TMP in membrane systems were mainly caused by colloidal matters causing turbidity and organic matters had slight influence.

Table 4. Summary of pilot-scale UF operation in Büyükçekmece water treatment plant

\begin{tabular}{|c|c|c|c|c|c|c|c|}
\hline & \multicolumn{3}{|c|}{ Conventional Plant } & \multicolumn{2}{|c|}{$\begin{array}{c}\text { Combination with } \\
\text { V-PSUF }\end{array}$} & \multicolumn{2}{|c|}{$\begin{array}{c}\text { Combination with } \\
\text { P-PSUF }\end{array}$} \\
\hline & FW & SP & FP & SP & FP & SP & FP \\
\hline Operation time, $(\mathrm{h})$ & - & - & - & 700 & 1200 & 700 & 1200 \\
\hline TMP, (mbar) & - & - & - & 150 & 40 & $400-750$ & $700-1200$ \\
\hline Turbidity, ( NTU) & $4.9-10.3$ & $0.23-0.96$ & $0.12-0.41$ & $0.01-0.05$ & $0.01-0.05$ & $0.01-0.05$ & $0.01-0.05$ \\
\hline $\mathrm{UV}_{254,}\left(\mathrm{~cm}^{-1}\right)$ & $0.05-0.07$ & $0.04-0.06$ & $0.04-0.05$ & $0.02-0.05$ & $0.03-0.04$ & $0.03-0.05$ & $0.03-0.04$ \\
\hline TOC, $\left(\mathrm{mg} \mathrm{L}^{-1}\right)$ & $4.65-5.93$ & $3.26-4.48$ & $2.82-4.53$ & $3.42-3.95$ & $2.67-4.38$ & $3.73-4.40$ & $3.12-4.46$ \\
\hline T. Coliform, (MPS $100 \mathrm{~mL}^{-1}$ ) & $4-60$ & 0 & 0 & 0 & 0 & 0 & 0 \\
\hline Flow rate $\left(\mathrm{L} \mathrm{h}^{-1}\right)$ & - & - & - & 40 & 40 & $150-280$ & $180-280$ \\
\hline Energy consumption (kwh) & - & - & - & $3-5$ & $4-5$ & $10-18$ & $15-25$ \\
\hline
\end{tabular}

FW: Feed water; SP: Sedimentation process; FP: Filtration process

Table 5. Summary of pilot-scale UF operation in Emirli water treatment plant

\begin{tabular}{|c|c|c|c|c|c|c|c|}
\hline & \multicolumn{3}{|c|}{ Conventional Plant } & \multicolumn{2}{|c|}{ Combination with V-PSUF } & \multicolumn{2}{|c|}{ Combination with P-PSUF } \\
\hline & FW & SP & FP & SP & FP & SP & FP \\
\hline Operation time, $(\mathrm{h})$ & - & - & - & 800 & 1150 & 800 & 1150 \\
\hline TMP, (mbar) & - & - & - & 45 & 30 & $600-1800$ & $400-1800$ \\
\hline Turbidity, ( NTU) & $1.76-69.6$ & $1.27-2.88$ & $0.14-0.47$ & $0.01-0.03$ & $0.01-0.03$ & $0.01-0.10$ & $0.01-0.10$ \\
\hline $\mathrm{UV}_{254,}\left(\mathrm{~cm}^{-1}\right)$ & $0.06-0.11$ & $0.04-0.07$ & $0.02-0.03$ & $0.03-0.05$ & $0.01-0.02$ & $0.03-0.05$ & $0.02-0.03$ \\
\hline TOC, $\left(\mathrm{mg} \mathrm{L}^{-1}\right)$ & $3.43-5.80$ & $1.88-3.55$ & $1.00-2.41$ & $1.67-2.93$ & $0.81-2.20$ & 1.91-3.09 & $0.89-2.32$ \\
\hline T. Coliform, (MPS $100 \mathrm{~mL}^{-1}$ ) & $4-370$ & 0 & 0 & 0 & 0 & 0 & 0 \\
\hline Flow rate $\left(\mathrm{L} \mathrm{h}^{-1}\right)$ & - & - & - & 40 & 40 & $70-220$ & $100-220$ \\
\hline Energy consumption (kwh) & - & - & - & $4-6$ & $4-6$ & $12-19$ & $10-15$ \\
\hline
\end{tabular}


Power consumption is mainly related with the magnitude of pressure applied and is one of major comparison criteria in membrane systems. Energy consumption values of two pilot-systems are given in Tables 4 and 5. V-PSUF had closer energy consumption in both plants around $5 \mathrm{kwh}$ while $\mathrm{P}$ PSUF consumed about 3 times more power. The big difference in energy consumption in two membrane systems were related with the operational modes and backwash interval frequency. In addition to high treatment efficiencies of turbidity and organic removal, vacuum driven membrane is superior on energy consumption comparison to pressure driven membranes.

\section{Conclusions}

In this study, treatment efficiencies of conventional processes alone and combination with UF membranes were evaluated. All studies were performed with two fullscale conventional water treatment plant and low-pressure pilot-scale UF membranes. Performance was made based on removal of TOC, turbidity, $\mathrm{UV}_{254}$ and energy consumption. In all studies, combined systems were superior on conventional systems alone and treatment efficiencies increased with the increasing of conventional processes. In comparison to low-pressure membrane types, vacuum-driven UF had higher removal efficiencies of turbidity, TOC and UV254. Additionally, vacuum-driven UF experienced less backwashing, served longer service time and consumed lower energy. Conventional treatment process alone had ability to remove all total coliform. Trihalomethane formation potential were lower in the effluent of UF-membrane system due to the higher organic matter removal of combined system.

\section{Acknowledgement}

Authors gratefully acknowledge the support to this study by Istanbul Water and Sewerage Administration (ISKI).

\section{References}

Ang W.L., Mohammad A.W., Hilal N. and Leo C.P. (2015), A review on the applicability of integrated/hybrid membrane processes in water treatment and desalination plants, Desalination, 363, 2-18.

Bai L., Liang H., Crittenden J., Qu F., Ding A., Ma J., Du X., Guo S. and Li G. (2015), Surface modification of UF membranes with functionalized MWCNTs to control membrane fouling by NOM fractions, Journal of Membrane Science, 492, 400-411

Bogati R., Goodwin C., Marcshall K., Leung K.T. and Liao B.Q. (2015), Optimization of Chemical Cleaning for Improvement of Membrane Performance and Fouling Control in Drinking Water Treatment, Separation Science and Technology, 50, 1835-1845.

Cakmakci M., Baspinar A.B., Balaban U., Uyak V., Koyuncu I. and Kinaci C. (2009), Comparison of nanofiltration and adsorption techniques to remove arsenic from drinking water, Desalination and Water reatment, 9(1-3), 149-154.

Chen X. and Deng H. (2012), Removal of humic acids from water by hybrid titanium-based electrocoagulation with ultrafiltration membrane processes, Desalination, 300, 51-57.

Choksuchart P., Heran M. and Grasmick A. (2002), Ultrafiltration enhanced by coagulation in an immersed membrane system, Desalination, 145, 265-272.
Goa W., Liang H., Ma J., Han M., Chen Z., Han Z.S. and Li G. (2011), Membrane fouling control in ultrafiltration technology for drinking water production: A review, Desalination, 272(1-3), 1-8.

Huang H., Schwab K. and Jacangelo J.G. (2009), Pretreatment for low pressure membranes in water treatment: A Review, Environ. Sci. Technol., 43(9), 3011-3019.

Mehwish N., Kausar A. and Siddiq M. (2014), Advances in Polymer-based Nanostructured Membranes for Water Treatment, Polymer-Plastics Technology and Engineering, 53(12), 1290-1316.

Metsämuuronen S., Sillanpääa M. and Bhatnagar M.M. (2014), Natural organic matter removal from drinking water by membrane technology, Separation and Purification Reviews, 43, 1, 1-61.

Papageorgiou A., Papadakis N. and Voutsa D. (2016), Fate of natural organic matter at a full-scale Drinking Water Treatment Plant in Greece, Environmental Science and Pollution Research, 23(2), 1841-1851.

Plakas K.V. and Karabelas A.J. (2012), Removal of pesticides from water by NF and RO membranes-A review, Desalination, 287, 255-265.

Qin J.J., Lay W.C.L. and Kekre K.A. (2012), Recent developments and future challenges of forward osmosis for desalination: a review, Desalination and Water Treatment, 39, 1-3.

Rojas-Serranoa F., Perez J.I. and Gomez M.A. (2015), Integrated in-line coagulation-aerated ultrafiltration for drinking-water production: A case study from laboratory to pilot plant, Journal of Environmental Science and Health, Part A: Toxic/Hazardous Substances and Environmental Engineering, 50(13), 1376-1385.

Shamsuddin N., Das D.B. and Starov V.M. (2015), Filtration of natural organic matter using ultrafiltration membranes for drinking water purposes:Circular cross-flow compared with stirred dead end flow, Chemical Engineering Journal, 276, 331-339.

Shao S., Qu F., Liang H., Li K., Yu H., Chang H. and Li G. (2015), Powdered activated carbon - membrane bioreactor operated under intermittent aeration and short sludge retention times for micro-polluted surface water treatment, International Biodeterioration \& Biodegradation, 102, 81-88.

Stoquart C., Servais P., Bérubé P.R. and Barbeau B. (2012, Hybrid Membrane Processes using activated carbon treatment for drinking water: A review, Journal of Membrane Science, 411, $1-12$.

Uyak V., Koyuncu I., Oktem I., Cakmakci M. and Toroz I. (2008), Removal of trihalomethanes from drinking water by nanofiltration membranes, Journal of Hazardous Materials, 152(2), 789-794.

Xu H., Chen W., Xiao H. and Hu X. (2014), Stability of an ultrafiltration system for drinking water treatment, using chlorine for fouling control, Desalination, 336, 187-195.

Yamamura H., Kimura K., Higuchi K., Ding Q. and Hafuka A. (2015), Tracking inorganic foulants irreversibly accumulated on lowpressure membranes for treating surface water, Water Research, 87, 218-224.

Yang L., Kim D., Uzun H., Karanfil T. and Hur J. (2015), Assessing trihalomethanes (THMs) and $\mathrm{N}$-nitrosodimethylamine (NDMA) formation potentials in drinking water treatment plants using fluorescence spectroscopy and parallel factor analysis, Chemosphere, 121, 84-91. 